\title{
Future-proof cities through governance experiments? Insights from the Resilient Melbourne Strategy (RMS)
}

\author{
Sebastian Fastenrath ${ }^{1} \&$ Lars Coenen ${ }^{2}$
}

\author{
${ }^{1}$ Melbourne Sustainable Society Institute, The University of Melbourne, Victoria 3010, Australia \\ sebastian.fastenrath@unimelb.edu.au \\ 2 Mohn Centre for Innovation and Regional Development, Western Norway University of Applied Sciences, Bergen, Norway; \\ Melbourne Sustainable Society Institute, The University of Melbourne, Victoria 3010, Australia, lars.coenen@hvl.no
}

This is an Accepted Manuscript of an article published by Taylor E Francis in Regional Studies on 23 April 2020 , available online: https://www.tandfonline.com/doi/abs/10.1080/00343404.2020.1744551?journalCode=cres20

\begin{abstract}
Established urban policy and planning approaches are ill-equipped to deal with the wicked nature of urban resilience problems and challenges. To break down bureaucratic silos and foster transformative change, 'governance experiments' are heralded as promising platforms for testing new ways of collaboration and urban innovation. This paper introduces an analytical framework to unpack the organisational principles and institutional structures of governance experimentation. It applies this framework on urban resilience actions in Melbourne as part of the Rockefeller 100 Resilient Cities Network. The case studies illustrate that governance experimentation requires active stakeholder and boundary management and acceptance to learn from failure.
\end{abstract}

Keywords

Urban resilience, governance experimentation, resilience action, transformational change

\section{Introduction}

In the face of increasingly tangible impacts of climate change, growing socio-economic inequalities and environmental degradation, the debates around futureproofing cities are gaining rapid momentum. Current city practices are often ill-equipped to deal with the complexities and the urgency of today's urban challenges (Elmqvist et al. 2019). To make cities more resilient and sustainable, the UN's Sustainable Development Goal 11 underlines the need for better urban planning and governance (UN 2015). However, how can cities 'better' plan and build capacity for what is generally considered to require transformative change towards a more sustainable future?

Urban resilience strategies and actions constitute relatively novel approach that challenges and potentially transforms urban policy and planning (Davidson and Gleeson 2018). During the last few years, building resilience has become a key objective for many cities in the face of acute and often interrelated environmental, social and economic challenges. One example is the Resilient Melbourne Strategy initiated through the Rockefeller Foundation's '100 Resilient Cities' (100RC) initiative, one of the most prominent city networks that advocates urban resilience activities. This strategy identifies place-based resilience challenges in metropolitan Melbourne, and implements actions to deliver, organize and coordinate urban services and infrastructures across a variety of contexts such as mobility, energy, housing, health, climate change, and social cohesion in new and more robust ways (Fastenrath et al. 2019). Scholars have described resilience as a new "policy metaphor for embedding 'foresight', robustness and adaptability into a variety of place-making and localist planning activities" (Coaffee 2013: 325).

While resilience thinking and practice have been criticized for conceptual slippage, model transposition from natural to social sciences and being potentially defensive of authoritarian and/or neo-liberal values (e.g. Beilin \& Wilkinson 2015; Cote \& Nightingale 2012; Kythreotis \& Bristow 2017; Leitner et al. 2018; MacKinnon \& Derickson 2013; Porter \& Davoudi 2012), others have acknowledged its status as a boundary object, called for a less dismissive view and highlighted the possibility of resilience for triggering new ways of urban governance (Duit et al. 2010; Rogers 2015; Schwanen 2016). The latter perspective resonates with the debates around resilience as a catalyst for transformational change through new cross-sectoral formations of actors and institutional 
structures (Brand \& Jax 2007; Davoudi 2012; Shaw 2012). Resilience thinking and practice, when enacted through inclusive processes that involve institutional learning, might discourage "planners from putting the emphasis on rigid and fixed plans and the attempt to command and control space and time" (Davoudi et al. 2013: 320).

Whether urban resilience strategies can deliver transformative change requires a more granular evidence base of the implementation processes and the outcomes of urban resilience actions (Coaffee et al. 2018; Fastenrath et al. 2019). More in-depth theoretical and empirical research is needed to further understand the ways in which resilience actions are implemented and shaping the capabilities of cities to innovate and transform their urban systems of provision in and across multiple urban domains.

In this paper we investigate the implementation of urban resilience actions and its transformative potential through the lens of 'governance experimentation' (Bos \& Brown 2012; Bulkeley et al. 2018; Caprotti \& Cowley 2017; Evans et al. 2018; Fuenfschilling et al. 2019; Raven et al. 2019; Sengers et al. 2016; Smeds \& Acuto 2018, Turnheim et al. 2018). This concept, often associated with urban sustainability transitions and/or transformations is defined as "purposive interventions designed to respond to the imperative for climate change responses in the city, and with a more or less explicit attempt to innovate, learn or gain experience" (Bulkeley \& Castán Broto, 2013, p. 362). Such governance experiments serve to reconfigure capacities, resources and agency of actors in urban contexts (Bulkeley et al., 2014; Bulkeley \& Betsill, 2013; Bulkeley \& Castán Broto, 2013; McGuirk, Dowling, Brennan, \& Bulkeley, 2015). By providing a space to negotiate problem definitions and understandings, claims to resources, authority or dominant ideologies, experiments restructure the local institutions and through that have the potential to contribute to deepstructural change, i.e. sustainability transitions (Hodson, Geels, \& McMeekin, 2017).

Increasingly the concept of governance experimentation is put to practice by mainstream policy and practice to test new cross-sectoral partnerships and forms of coordination to reshape and renew urban policy processes (Bulkeley, Castán Broto, \& Maassen, 2011; Frantzeskaki et al. 2017; Moore, de Haan, Horne, \& Gleeson, 2018). The IPCC's 'summary for urban policy makers' concludes that what is required are transitions in social and ecological systems driven by policies that enable collaborative multi-level-stakeholder partnerships between public and private sectors, civil society and academia (IPCC 2018).

There is wide agreement that cities need new governance approaches that are more inclusive, collaborative, reflexive, and long-term (e.g. Elmqvist et al. 2019, Webb 2018). Governments need to restructure activities that can break down bureaucratic silos and innovate beyond conventional 'predict-then-act' planning approaches (e.g. Davoudi et al. 2013). So far, the discussion around governance experimentation in city contexts has predominantly been linked to so-called living labs, urban laboratories, or transition labs (e.g. Bulkeley et al. 2018; Fuenfschilling et al. 2019; Nevens et al. 2013). Albeit sympathetic concepts that emphasize inclusivity, participation and processes of open and democratic innovation, they at the same time run the risk of blackboxing governance experimentation and keeping its organizational principles and institutional processes opaque.

To better understand how urban governance experiments are implemented and seek to drive transformational change, the paper introduces a framework that draws on Ferraro et al.'s (2015) theorization of tackling grand challenges through robust action. This framework is shaped to analyze single governance experiments focusing on three dimensions: coordination \& structure, goals \& understandings, and processes. Applying this framework by analyzing actions of the Resilient Melbourne Strategy, the paper demonstrates how this approach is helpful for city practitioners and researchers to assess and compare actions at different stages.

The paper is structured in the following way. The next section highlights the debates around urban resilience and outlines the current understandings and challenges. Then the paper introduces the analytical framework and discusses urban experimentation. The following section discusses the empirical insights into Resilient Melbourne Strategy actions as case studies before concluding thoughts are presented in the last section.

\section{Urban resilience - from crisis management to reduction of 'chronic stresses'}

The conceptual foundations of resilience go back to the 1970s when engineers used the term to describe the capacity of materials to return to pre-existing conditions after being exposed to physical stresses. This idea was 
adopted by ecologists and used to describe how ecosystems return to stable states (equilibrium) after disturbances (Holling 1973). Linking social and ecological systems and introducing ideas for a socio-ecological resilience to analyze human-environment dynamics opened the discussion for social sciences (Berkes 2007; Berkes \& Folke 1998; Folke 2006). While rationales of systemic 'bouncing-back', 'absorbing', and 'adapting' to shocks and hazards dominated the early debates, a wider understanding of resilience exists today. It is increasingly linked to ideas of 'proactive', solution-oriented actions that respond to systemic 'stresses' - challenges that disturb urban systems over a longer period of time.

During the last decade resilience has become a key goal for cities in the face of acute and often interrelated environmental, social and economic challenges. Numerous cities have initiated resilience strategies and implemented actions to 'future-proof' their cities. However, resilience thinking and practice are contested, particularly in the context of urban governance and public service provision (e.g. Beilin \& Wilkinson 2015; Cote \& Nightingale 2012; Kythreotis \& Bristow 2017; Porter \& Davoudi 2012). Critical scholars have found resilience initiatives often to be 'externally' and 'topdown' steered, lacking citizen participation and not open to alternative ways of collaboration and delivery of actions (e.g. Leitner et al. 2018; MacKinnon \& Derickson 2013). More specifically, they have critiqued resilience initiatives as an instrument of neoliberalism, characterized by prioritizing (vested) economic interests, undermining citizen engagement and reducing tasks of public authorities (e.g. Fainstein 2018; Hay \& Muller 2012).

The increasing heterogeneity of opinions on urban resilience is the result of the continual diversification of understandings and practices (Meerow et al. 2016). During the last few years, resilience shifted from a dominant 'reactive' disaster management toward a more 'pro-active' and self-reflective policy-making tool to drive urban transformational change (Coaffee et al. 2018; Fastenrath et al. 2019; Shaw \& Maythorne 2013). Moreover, the understanding of resilience as a static condition rather than an ongoing process has been challenged (e.g. Boschma 2015; Davoudi, Brooks \& Mehmood 2013; Martin et al. 2015; Simmie \& Martin 2010). Therefore, the critical literature on urban resilience often seems one-sided, neglecting the increasing multiplicity of resilience (Schwanen 2016) and lacking scrutiny of concrete actions and practice. Urban resilience-building actions have diversified from 'reactive' disaster management toward more 'pro-active' and self-reflective policy-making tools to drive transformational change (Coaffee et al. 2018).

The understanding of urban resilience as the capacity to tackle systemic 'shocks' and 'stresses' can be seen as a significant modification. Resilience is no longer solely understood as a 'back to normal' or back to pre-disaster status. In other words: there is a shift from resilience as a systemic 'bouncing back' toward also 'bouncing forward'. This changed resilience thinking is also linked to an understanding from systemic equilibrium towards a more open, experimental, and non-linear ecosystemthinking. These 'evolutionary' perspectives of resilience, as a critical response to the static understanding, are some of the most recent and important turning points in conceptualizing and understanding resilience. Following the definition of Davoudi et al., the approach of 'evolutionary resilience' can be understood as a process of transformative capacity-building through experimentation, social and institutional 'learning by doing', and "cultivating flexibility, resourcefulness and cooperative networks" (2013: 319). We argue that this theoretical thinking further opens the discussion for resilience as an 'agenda of change' (Rogers 2015) and helps to analyze resilience actions and their embeddedness in urban systems over time. It also (re)opens the debates of resilience as an innovative governance model to deal with processes of complex change (Duit 2016; Duit et al. 2010).

\section{Cities as key arenas for resilience-building actions and transformational change}

The debates about urban resilience resonate with discussions around cities as key arenas for experimentation to drive transformational change. It becomes clear that the grand challenges we are facing today call for innovation in collective action and urban governance (e.g. Bulkeley \& Castan Broto 2013; Burch et al. 2014; Elmqvist et al. 2019). To identify and implement solutions, knowledge and expertise need to be bundled from a variety of stakeholders linked to the public, private, academic and civic sector.

At present, urban resilience actions and strategies are mostly monitored by quantitative indicators and tools (e.g. Arup's City Resilience Index, Arup 2019). These assess resilience building actions relative to achieving (static) conditions of urban resilience but pay less 
attention to dynamic and transformative socio-political processes (Chelleri et al. 2015; MacKinnon et al. 2012; Matyas \& Pelling 2015; Pelling \& Manuel-Navarrete 2011; Rogers 2015). Therefore, analytical frameworks are needed that help to investigate how strategies are actually translated into actions to complement quantitative analysis of actions' outcomes. In doing so, a closer look at goals and interests of specific resilience actions is needed to explore how, and particularly by and for whom, urban resilience practices are initiated (Cretney 2014; Meerow and Newell 2016; Shaw \& Maythorne 2013).

\section{Analyzing urban resilience as urban governance experimentation}

Empirical research on the implementation processes of resilience actions need more attention to understand the underlying experimental forms of capacity-building and agency; and based on this, to inform policy-makers and practice decisions (e.g. Coaffee et al. 2018; Rogers 2015). Therefore, we argue that urban resilience actions need a re-conceptualization as 'governance experiments'. The increasing number of contributions on 'urban experimentation' or 'experimental cities' have paid attention to a number of case studies and potential transformational areas (e.g. Bulkeley et al. 2018; Caprotti \& Cowley 2017; Evans et al. 2016; Fuenfschilling et al. 2019; Sengers et al. 2016). However, a conceptualization of urban resilience actions as governance experiments is lacking. The meaning and functions of urban experimentation differ fundamentally to 'classical' experiments in natural or engineering science (Turnheim et al. 2018). Rather they should be understood as trial and testing processes of novel institutional arrangements to govern urban systems.

But how do cities and local governments organize urban experimentation? What are its organizational design principles? To unpack governance experiments we draw on Ferraro et al.'s (2015) theorization of tackling grand challenges through 'robust action'. The authors draw on the sociological concept of robust action (e.g. Padgett \& Ansell, 1993; Padgett \& Powell, 2012) which is understood as an open-ended practice in which actors have the ability to adapt over time to new and developing situations. In a context of grand challenges such as poverty alleviation and climate change consequences Ferraro et al. (2015) have analyzed strategies focused on how public sector actors and organizations coordinate and restructure processes of transformative change. They identified three key components to such strategies (see Ferraro et al. 2015):

- 'Participatory architecture': a structure and rules of engagement that allow diverse and heterogeneous actors to interact constructively over prolonged timespans.

- 'Multivocal inscription': interpretative flexibility around boundary objects to promote coordination without requiring explicit consensus.

- 'Distributed experimentation': iterative action that generates small wins, promotes evolutionary learning, and increased engagement, while allowing unsuccessful efforts to be abandoned.

We argue that these three underlying complimentary dimensions can be used and applied as an analytical framework to analyze governance experimentation. Focusing on these three analytical entities allows to compare single urban governance experiments such as actions related to resilience-building, sustainability transitions or other initiatives that are based on new governance models.

\section{Participatory architecture (coordination and structure)}

Governance experiments cannot be understood without the actors who initiate and drive learning processes and interact with other actors within this initiative. The 'architecture' of actions is seen as key to providing new structures and longer-term involvement of a range of actors. As Ferraro et al. explain: "Institutional change is not the result of individual entrepreneurial action, but rather, the efforts of multiple individuals and organizations that purposefully spearhead change and mobilize cooperation" (2015: 368). Therefore, to create knowledge on how governance experiments are constructed, we need to understand how they are organized and coordinated. In other words, we need to identify the actors and their interactions to understand the underlying structures and processes. There is broad agreement that pathways of change rely on processes of agency (see Garud and Karnøe 2001; Garud et al. 2010). Coenen et al. (2010) demonstrate how agency shapes interactions and learning processes in local niche experimentation' driven by intermediary actors. However, we need to better understand how the drivers of experiments are interacting with higher policy levels 
(state, national, and inter-national levels) (see Smeds \& Acuto 2018, Kythreotis 2018). To overcome challenges in creating cross-sectoral and cross-scale collaboration, Cash et al. (2006) suggest 'boundary or bridging organizations' than can fulfill an intermediary function by collecting and sharing information with participating stakeholders.

Multivocal inscription (goals and understandings)

This second type identified by Ferraro et al. (2015) is understood as the interpretive flexibility of common activities. This dimension draws on stakeholders' different expectations and understandings of problems and the tools to solve these. It helps to identify the discursive and material kit to drive longer-term actions. As Cash et al. (2006) pointed out, the challenge in creating change through new cross-scale cooperation is the plurality of interests. Different actors seek to reach different goals based on new cooperation. To overcome this challenge, common goals and actions need to be identified through boundary or bridging organizations. Authors have pointed out, one of the attractions of resilience as a boundary object and bridging concept is that it allows multiple knowledge domains to interface (Brand \& Jax 2007, Meerow \& Newell 2016, Welsh 2014).

\section{Distributed experimentation (processes)}

The third dimension, distributed experimentation, refers to the different processes of coordination of interventions. Ferraro et al. (2015) give examples of how purpose-driven experimentation may lead to novel institutional arrangements and socio-technical configurations. They argue, if experiments are understood and applied as on-going and reflexive interventions, and include diverse actors with different understandings, there is increasing potential for innovation. We argue that urban governance experimentation is about flexibility, self-reflectivity, learning and knowledge transfer. Lessons learned can increase the transformative capacity of actors embedded in their socio-technical systems. However, as Ferraro et al. highlight: "[...] not every experiment will prove successful, at least not in real-time. This could be because the experiment has gone 'wrong' in the sense that it failed to deliver the hoped for results. Or the experiment itself can lead to the emergence of new and previously unidentified concerns" (2015: 377).

\section{Resilient Melbourne Strategy (RMS) Actions}

Analyzing the implementation processes of the Resilient Melbourne Strategy provides the opportunity to more keenly assess urban resilience actions. In 2013, the City of Melbourne became a member of the 100RC network, under the condition that all 32 local governments of metropolitan Melbourne participated in the initiative. More than 1000 individuals and organizations from public, private and academic sectors across Melbourne helped to identify context-specific challenges, which were subsequently incorporated into the Resilient Melbourne Strategy (RMS), (Resilient Melbourne 2016). These challenges are linked to a range of natural and human-induced related hazards as well as socioeconomic and socio-technical challenges.

The results of the assessment of Melbourne's 'acute shocks' (sudden events that threaten a city) covered the following aspects: bushfires, floods, heatwaves, epidemics, infrastructure-related emergencies and extremist acts. Identified 'chronic stresses' (challenges that weaken the fabric of a city on a day-to-day or cyclical basis) were: rapid population growth, social inequality, pressures on natural assets, unemployment, climate change, alcoholism and family violence (Resilient Melbourne 2016). The rapid population growth the city is facing is undoubtedly the dominant problem. It has implications for the population, but also, for authorities that provide infrastructure and other public services and facilities (e.g. energy, transport, water, sewerage, green space, schools, health services, etc.). The process resulted in 33 potential strategy actions to tackle Melbourne's identified challenges (Resilient Melbourne 2016). Since 2017, a number of these actions have been prepared and partly implemented (see fig. 1) under the lead of the Resilient Melbourne Delivery Office (RMDO). The RMDO seeks collaborations across state and local government, private and not-for profit actors and academia, and monitors and reports on progress of actions. 


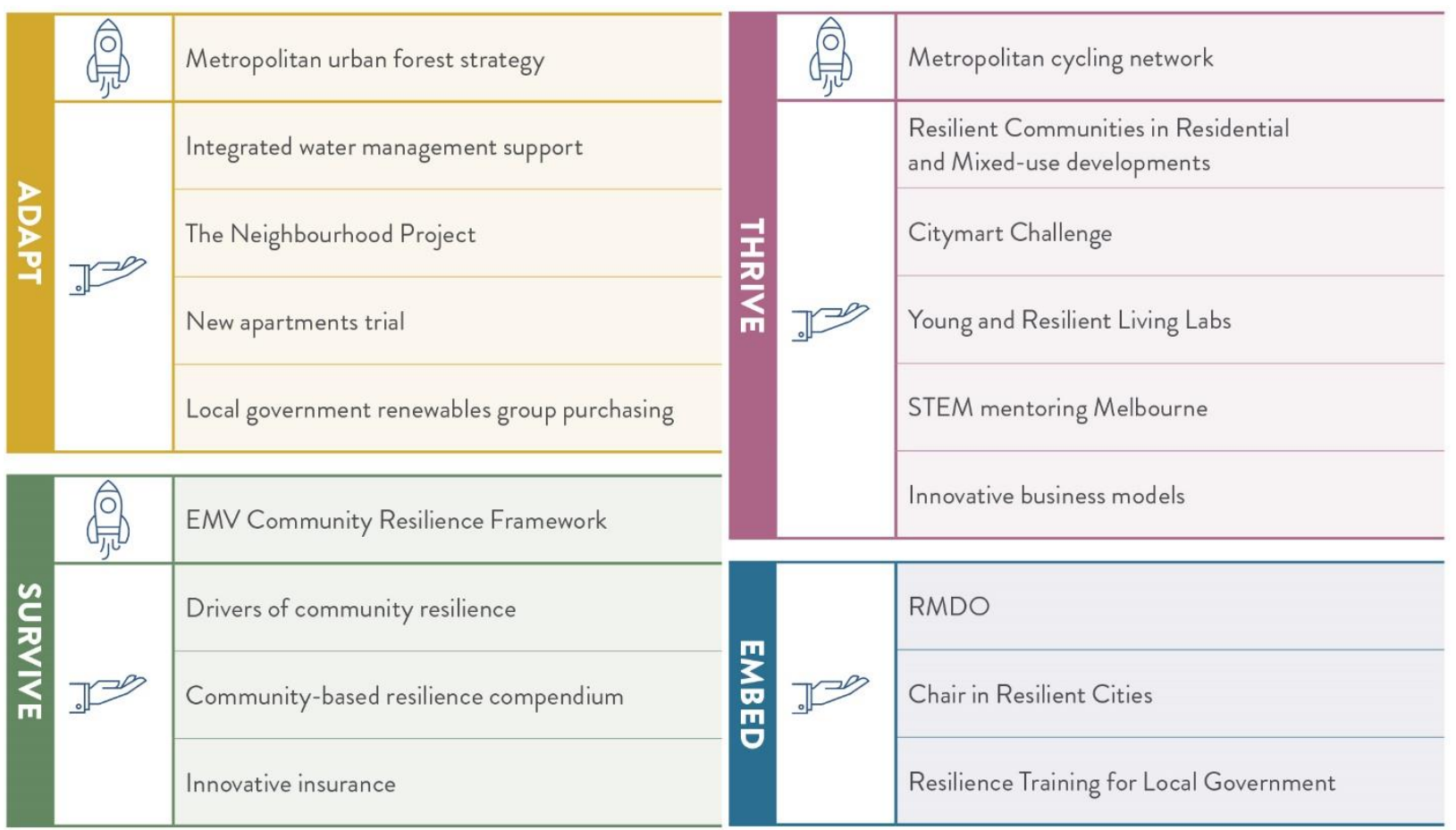

(0) Flagship Action

Figure 1. Overview of Resilient Melbourne Strategy Actions (source: Resilient Melbourne 2019²).

\section{Research design and data}

The empirical insights are based on an ongoing research project conducted in cooperation with the RMDO. Using Resilient Melbourne Strategy Actions (RMSAs) as case studies, the goal of the project is to gain knowledge about how governance experimentation might help to lead transformative change by analyzing structures, understandings and key processes. For this study we selected two 'Flagship Actions' - 'Metropolitan Urban Forest Strategy' (renamed to 'Living Melbourne' - the metropolitan urban forest strategy) and 'Metropolitan Cycling Network'. In comparison to 'Supporting Actions' (see fig. 1), Flagship Actions are "key initiatives with the potential for metropolitan-wide involvement and transformational outcomes" (Resilient Melbourne 2016: 3). These two actions have been selected as comparative case studies because of their similarities in objective and remit - i.e. to drive transformational change on a metropolitan scale yet being deployed in different urban systems. Also, they started at a similar time and involved stakeholders from the public, private and academic sector.

We explored these two actions, based on a qualitative research design that includes interviewing and document analysis. Referring to Flick (2004), the triangulation of methods is helpful when collecting and interpreting primary data.
Combining different sources helps to ensure legitimacy of a case study-based qualitative research design (Yin 2014). The data was collected through semi-structured interviews and document analysis between July and December 2018 (see fig. 2). Participants were selected through advice by the RMDO and via snowball sampling. The interviewees were directly involved in the actions or are experts of the actions' fields. Case study-related materials such as policy documents and project reports and drafts were provided by the RMDO or collected through desktop research. Aligned with the analytical framework, the interview guide was structured into four key topics that were discussed for each action: stakeholders; roles and motives in the action; goals and understandings; processes of learning; and knowledge transfer. 


\begin{tabular}{|c|c|c|c|c|c|}
\hline \multicolumn{3}{|c|}{$\begin{array}{l}\text { Metropolitan Urban } \\
\text { Forest Strategy }\end{array}$} & \multicolumn{3}{|c|}{ Metropolitan Cycling Network } \\
\hline \multicolumn{3}{|c|}{9 semi-structured interviews } & \multicolumn{3}{|c|}{10 semi-structured interviews } \\
\hline Date & Sector & Code & Date & Sector & Code \\
\hline $15 / 08 / 18$ & NGO & FOR-1 & $18 / 07 / 18$ & Local Government (Other) & CYC-1 \\
\hline $24 / 08 / 18$ & Local Government (Urban planning) & FOR-2 & $05 / 10 / 18$ & Local Government (Urban planning) & CYC-2 \\
\hline $27 / 08 / 18$ & Local Government (Urban planning) & FOR-3 & $17 / 10 / 18$ & Local Government (Urban planning) & CYC-3 \\
\hline 04/09/18 & Local Government (Urban planning) & FOR-4 & $25 / 10 / 18$ & Academia & CYC-4 \\
\hline $07 / 09 / 18$ & Academia & FOR-5 & $26 / 10 / 18$ & Academia & CYC-5 \\
\hline 09/11/18 & Private Sector & FOR-6 & $07 / 11 / 18$ & Local Government (Urban planning) & CYC-6 \\
\hline $22 / 11 / 18$ & Local Government (Urban planning) & FOR-7 & 09/11/18 & Local Government (Urban planning) & CYC-7 \\
\hline $29 / 11 / 18$ & Local Government (Urban planning) & FOR-8 & 09/11/18 & Local Government (Urban planning) & CYC-8 \\
\hline $12 / 12 / 18$ & Local Government (Other) & FOR-9 & $\begin{array}{l}12 / 11 / 18 \\
12 / 12 / 18\end{array}$ & $\begin{array}{l}\text { Local Government (Urban planning) } \\
\text { Local Government (Other) }\end{array}$ & $\begin{array}{l}\text { CYC-9 } \\
\text { CYC-10 }\end{array}$ \\
\hline \multicolumn{3}{|c|}{$\begin{array}{l}\text { Documents } \\
\text { - 'Melbourne Metropolitan Urban Forest Strategy, Local } \\
\text { Government Workshop, Summary Report' (10/2017) } \\
\text { - 'Melbourne Metropolitan Urban Forest Strategy, Multi- } \\
\text { Stakeholder Workshop, Summary' (12/2017) } \\
\text { - 'Melbourne Metropolitan Urban Forest Strategy, } \\
\text { Stakeholder Workshop' (07/2018) } \\
\text { - 'Living Melbourne - The Melbourne Metropolitan Urban } \\
\text { Forest Strategy' + Technical support document -draft } \\
\text { (10/2018) } \\
\text { - 'Living Melbourne - Our metropolitan urban forest + } \\
\text { Technical support document - draft (02/2019) } \\
\text { - 'Living Melbourne' - Our metropolitan urban forest + } \\
\text { Technical support document (06/2019) }\end{array}$} & \multicolumn{3}{|c|}{$\begin{array}{l}\text { Documents } \\
\text { - 'Metropolitan Cycling Network - Workshop \#1, Summary' } \\
\text { (09/2017) } \\
\text { - 'Metropolitan Cycling Network - Workshop Two, Summary' } \\
\text { (11/2017) } \\
\text { - Victorian Cycling Strategy 2018-28, Increasing cycling for } \\
\text { transport (VIC Gov) }\end{array}$} \\
\hline
\end{tabular}

Figure 2. Overview of data collection.

\section{Metropolitan Urban Forest Strategy}

The flagship action of Resilient Melbourne is the Metropolitan Urban Forest Strategy, given the large number of actors involved, and the international attention it gains, particularly through the 100RC network which actively promotes this action (100RC 2019). While green infrastructure in Melbourne has been supported and initiated by a number of local governments, a metropolitan-wide strategy is lacking (Resilient Melbourne 2016). This action was initiated in a partnership between the RMDO and 'The Nature Conservancy' (TNC), a non-governmental organization and 'platform partner' of the 100RC network. The overarching goal of this action is to develop a strategy that helps to increase the tree canopy cover and overall vegetation of the city region to tackle a range of challenges, including loss of biodiversity, climate change and related hazards like heatwaves and flooding, and issues around physical and mental health.
The underlying goal of this action is to link existing urban green infrastructure, reforestation and other environmental initiatives (Resilient Melbourne 2016). In late 2018, the action was re-named 'Living Melbourne The Metropolitan Urban Forest Strategy' (Resilient Melbourne 2019).

\section{Participatory architecture (coordination and structure)}

The action is organized through RMDO and TNC. These two key actors curate the network of participating actors and set the 'rules of engagement' by inviting other actors. Based on this reading, which is supported by interview insights (e.g. FOR-5), the action can be interpreted as a 'top-down'-driven process. To date, more than 60 stakeholders from public and private sectors, NGOs and academia have been involved in shaping this action (FOR1, Resilient Melbourne 2019). The Resilient Melbourne initiative and its actions has established a new platform for cross-sectoral and cross-scale urban governance but with a strong presence of public sector stakeholders. Membership 
to this platform is predicated on whether the respective stakeholders contributes with relevant knowledge and expertise.

In particular, knowledge about related urban planning processes was brought to the table by urban planners, forestry and utility experts of local governments; representatives of state government planning authorities; and researchers from different disciplines. Compiling this knowledge was crucial to set targets, develop concrete strategies but also to identify challenges and barriers.

A wider 'opening' to the general public has not yet happened, but is planned as soon as the strategy framework is set (FOR-1). The evolution of the action's structural architecture shows it is flexible enough to cope with a growing diversity and heterogeneity of stakeholders. This includes also 'bottom-up' actors such as smaller networks of local governments, NGOs and grassroot movements. One example is the network 'Greening the West', an initiative that supports communities in Melbourne's western suburbs through the development of green infrastructure (FOR-4, Resilient Melbourne 2019). In addition, two external private sector actors have been involved in a more marginal role. DigitalGlobe and Trimble, also 100RC platform partners, provided satellite images which helped mapping Melbourne's green and open spaces.

Multivocal inscription (goals and understandings) While there is clarity around the action's overarching goal in increasing Melbourne's green infrastructure to tackle a range of socio-ecological challenges, there is 'interpretative flexibility' around single aspects of the action. For example, the observed debates around definitions of canopy cover, vegetation, targets and measures, underlines the openness, flexibility and processual logics of this action (FOR-5, Resilient Melbourne 2019). The ongoing discussions around single definitions and goals (such as the percentage of increase of canopy cover in the city) can be seen as important drivers to facilitate on-going articulation of different stakeholders' interests in the action. Four multistakeholder workshops, summary documents, and report drafts which were open for comments, guided the development of the strategy, incorporated different stakeholder perspectives; and probably most importantly, they helped to review and adjust the strategy as it progressed (Resilient Melbourne 2019). The renaming of the action in late 2018 to 'Living Melbourne - The Melbourne Metropolitan Urban Forest Strategy' also reflects how the scope of strategy was deliberately opened-up beyond environmental policy to include issues of general well-being and livability.

\section{Distributed experimentation (processes)}

In the action experimentation is primarily enacted through ongoing debates over the last two years in stakeholder workshops and engagement through reports. The engagement in this action, particularly the participation in the workshop series, has been important to generate and exchange knowledge between local and state government authorities, the private sector, NGOs and academia. The workshops led to incremental learning about challenges, potential solutions and the experiences of others in the action. A representative of local government and expert in urban forestry highlighted that the action's processual approach helps to "break down silos and lead to intersectoral thinking" (FOR-7). Another local council representative said this action has led to learning processes and exchange between councils which usually do not regularly cooperate, and therefore helps to understand "who else is in the space" (FOR-8). Other interviewees said, the action helped to learn about the challenges of and solutions by other actors (FOR-1). Despite the long process of exchange and the released strategy document, there is a debate around how the strategy can be implemented in the next step.

\section{The Metropolitan Cycling Network}

Cycling was identified as the second priority area in the RMS and is seen as an important way to tackle socioecological challenges related to traffic congestion, pressures on infrastructure, pollution and health issues (Resilient Melbourne 2016). While some local councils within metropolitan Melbourne have played a driving role in supporting cycling and establishing cycling infrastructure, there are others lagging behind or disconnected from other local councils. Therefore, a key goal of this action is to develop cycling paths and corridors that connect the whole metropolitan Melbourne. This action, described as "planning and coordination initiative" (Resilient Melbourne 2016: 114), 
is closely tied to the objectives of the Victorian state government in supporting active transport and cycling commitments in 'Plan Melbourne', the metropolitan planning strategy that defines the future shape of the city and state over the next decades (VIC Gov 2016). As the key driver of this resilience action, Resilient Melbourne seeks to pool knowledge from academia, government agencies on different levels and cycling advocacy groups. Building on existing initiatives, the goal is to bring together key stakeholders and encourage "local government and infrastructure agencies to build new bicycle paths" (Resilient Melbourne 2016: 114).

\section{Participatory architecture (coordination and} structure)

The action is coordinated by the RMDO, and relies on close collaboration between local municipalities and state government transport bodies. At the early stages of the action, in 2017, the 100RC platform partner and consultancy company Jacobs played an important role as facilitator of two kick-off workshops. Attendees of these workshops were representatives from state government agencies, each of Melbourne's six urban 'sub-regions' and advocacy groups (CYC-1, CYC-6). After Jacobs' facilitating role ended after convening the two workshops, the action is mainly driven by the action's 'steering group', a network of representatives of the public sector and advocacy groups under the lead of Resilient Melbourne (CYC-7,8,9). This group seeks to further open the action's structure for a growing and more heterogenous actor network (CYC-1,7). While Resilient Melbourne is seen as a novel "advocate in raising the profile for cycling and shaping a message" (CYC-9), its limited power to directly influence planning was highlighted as a possible barrier to achieving transformative outcomes (CYC-6-9).

Multivocal inscription (goals and understandings)

As a Resilient Melbourne representative described, the goal of the overarching action is Melbourne's "transformation to a cycling city" (CYC-10). By establishing a city-wide cycling network, the key goal is to make cycling safer and a more practical alternative to car travel (CYC-10, Resilient Melbourne 2016). While there was broad agreement among interviewees around the necessity of transformational change around cycling, the interviews also revealed 'interpretative flexibility' around this resilience action. Referring to similar initiatives that target metropolitan-wide cycling, the outcomes and the added value of this action were partly questioned by interviewed planners from different local governments (CYC-6-9). Nevertheless, there was agreement that the action helps to further raise attention for the topic in Melbourne and might trigger further support through higher policy levels.

\section{Distributed experimentation (processes)}

Similar to the Metropolitan Urban Forest Strategy, workshops have been the main vehicles for experimentation. Initially, these were viewed positively by the participants because they brought together many stakeholders of Melbourne's cycling 'eco-system' to discuss the challenges of transforming cycling infrastructure (CYC-3,6-10). One interviewee described how helpful these workshops were in exploring and discussing the barriers local governments face in planning and building cycling infrastructure (CYC-7). Identified was the lack of power of local governments in making planning decisions. While local governments (city councils) are responsible for implementation of planning processes and management of infrastructure, the planning decisions are made at the state government level. Therefore, a policy level is missing that sits between the 32 local governments, which form metropolitan Melbourne, and the state government.

Over time, however, the action lost part of its momentum (CYC-6-8). Interviewees explained that it is unclear 'what' the action is seeking to achieve and 'how', apart from building up a larger stakeholder network. More specifically, the overlap of similar initiatives in mapping Melbourne's cycling infrastructure, was mentioned by different representatives of local councils (CYC-3,4,6-9). One council representative pointed out: “We don't need a new plan, we need implementation of infrastructure" (CYC-9). The lack of common understanding and goals might be related to the complexity and the short life time of the action relative to the scope and scale of infrastructural change. As Albrechts explained, the challenges in finding solution to complex problems in planning depend on the "ability to combine the creation of strategic visions [...] and the development and promotion of common assets" (2004: 743). All interviewees described that a major barrier to creating a common vision around cycling in Melbourne is the lacking support from state government and the 
general political willingness to support and quickly transform cycling infrastructure.

\begin{tabular}{|c|c|c|}
\hline & $\begin{array}{l}\text { Metropolitan Urban } \\
\text { Forest Strategy }\end{array}$ & Metropolitan Cycling Network \\
\hline & \multicolumn{2}{|c|}{ Participatory architecture } \\
\hline Coordination & Public-NGO partnership & $\begin{array}{l}\text { Public-private partnership (initially), then public } \\
\text { sector driven }\end{array}$ \\
\hline \multirow[t]{4}{*}{ Structure } & Heterogeneous network with participants from & Heterogeneous network with participants from \\
\hline & different sectors: public, private, academia, NGO & different sectors: public, private sector, NGO \\
\hline & Participatory 'rules of engagement' and inclusive & Participatory 'rules of engagement', inclusive \\
\hline & Increasing numbers and interest & Stagnating number of participants and interest \\
\hline \multirow{3}{*}{ Goals } & \multicolumn{2}{|c|}{ Multivocal inscription } \\
\hline & Increase tree canopy cover and overall vegetation & $\begin{array}{l}\text { Develop cycling paths and corridors that connect } \\
\text { all of metropolitan Melbourne }\end{array}$ \\
\hline & $\begin{array}{l}\text { Transforming socio-ecological systems through } \\
\text { 'nature-based solutions' }\end{array}$ & $\begin{array}{l}\text { Transforming socio-technical systems through } \\
\text { (hard) infrastructure extension and development }\end{array}$ \\
\hline \multirow[t]{2}{*}{ Understandings } & $\begin{array}{l}\text { Multiple understandings of single actions } \\
\text { aspects but general alignment }\end{array}$ & $\begin{array}{l}\text { Multiple and divergent understandings of } \\
\text { goals and responsibilities }\end{array}$ \\
\hline & \multicolumn{2}{|c|}{ Distributed experimentation } \\
\hline \multirow[t]{3}{*}{ Processes } & $\begin{array}{l}\text { Key platform for collaboration and learning: } \\
4 \text { multi-stakeholder workshops }\end{array}$ & $\begin{array}{l}\text { Key platform for collaboration and learning: } \\
2 \text { multi-stakeholder workshops }\end{array}$ \\
\hline & $\begin{array}{l}\text { Workshops as vehicles for guiding the strategy, } \\
\text { including different stakeholder perspectives and } \\
\text { reviewing the strategy as it progressed (open- } \\
\text { ended thinking). }\end{array}$ & $\begin{array}{l}\text { Workshops as initial platforms for collaboration } \\
\text { and problem understanding }\end{array}$ \\
\hline & $\begin{array}{l}\text { Building on existing (local) knowledge and } \\
\text { institutional structures }\end{array}$ & $\begin{array}{l}\text { Building on existing (local) knowledge and } \\
\text { institutional structures }\end{array}$ \\
\hline
\end{tabular}

Figure 3. Overview case study analysis

\section{Discussion}

The introduced framework, based on the three-fold approach (see fig. 3), has demonstrated to be a valuable entry point to unpack governance experimentation in Resilient Melbourne into concrete organizational guidelines and principles for transformative change. These organizational guidelines and principles seek to lend great specificity how to arrange purposive interventions with an explicit attempt to innovate, learn or gain experience and to reconfigure urban governance arrangements. First, it provides guidance on how to design and implement innovation and experimentation projects seeking to drive transformative change and; second, it helps to monitor and evaluate such projects for the purpose of achieving 'fuzzy' long-term programmatic objectives and to adjust such experiments over their life course.
Structured and ongoing assessment is crucial for city practitioners and policy makers in order to leverage and scale up experimental actions and to generate impact beyond the direct boundaries, stakeholders and networks of a project and increase the innovation capabilities of the local government at an organizational level (for similar conclusions, see a recent OECD (2019) report on enhancing innovation capacity in city government).

By applying the introduced framework, our research on resilience-building actions in Melbourne has illustrated how local government can demonstrate leadership in facilitating transformative change by orchestrating innovation and cooperation within and between local governments and other urban stakeholders. More importantly, the insights have shed light on the challenges that are linked to governance experiments for transformative change. Three key aspects can arguably be highlighted: 


\section{Multi-stakeholder collaboration and boundary management}

Our insights around the coordination and structure (participatory architecture) have highlighted the crucial role of and responsibility for 'boundary management' (Cash et al. 2006). To initiate, orchestrate and facilitate a functional and continuous platform for knowledge exchange and collaboration across different institutional sectors and territorial jurisdictions, a boundary management is required that marshals sufficient convening power. 'Boundary managers' operating within and across internal and external organizational silos are critical to introduce new ways of governance and to test and adjust those in order to overcome institutional gridlocks and to identify and renew institutional barriers and lock-ins. Similar roles and responsibilities are increasingly suggested in the literature with reference to 'chief innovation officers' (OECD 2019) or 'chief exploration officers' (Acuto 2018) within local governments and administrations. Boundary management is integral to the scope of the 'Resilient Melbourne Delivery Office' under the lead of its 'Chief Resilience Officer' and could even be seen as one of its primary organizational missions. In light of an absent metropolitan governance structure and the risk for fragmentation of urban systems, the Resilient Melbourne Delivery Office has de facto initiated and shaped collaboration and coordination structures across different stakeholders for urban greening and cycling. Our findings suggest that there is greater legitimacy for the convening role of the Resilient Melbourne Delivery Office in urban greening while there is more institutional inertia in the case of cycling. This could be explained by the relative newness of urban greening and/or nature-based solutions as an area of attention and responsibility for cities and its appeal as an effective climate change adaptation solution, whereas cycling sits more firmly within the traditional portfolio of planning departments in local and state government, creating risk for competition and/or duplication of responsibilities.

\section{The paradox of specifying the boundary object}

The second challenge is that successful 'boundary management' needs a suitable 'boundary object' that allows for multivocal inscription from a diverse set of stakeholders. An open, transparent and ongoing process of identifying and delineating problems, articulating the interests of different stakeholders as well as the capabilities and resource that they can mobilize is key to drive collective capacity building for transformational change.

Through continuous dialogue, governance experiments generate the collective vocabulary to speak about the challenges at hand that result in accountability and ownership within the platforms' participants. As the action 'Metropolitan Urban Cycling Network' illustrates, however, experiments can get stuck in vested interests and diverging understandings as a consequence of institutional path dependencies. When the problem framing of the boundary object - in this case 'the cycling network' - gets dominated by traditional institutional logics - here, transport infrastructure planning - it runs the risk of a premature closure that precludes transformative change as it allocates old solutions to new problems. This undermines the collective understanding of the boundary objects and may drive away relevant stakeholders that feel marginalized by the dominant problem framing. The urban forest case illustrates, on the contrary, how the meaning of the boundary object has evolved successfully over time. It has gradually acquired increasing numbers in terms of different stakeholders 'buying into' the concept yet retaining a sufficient degree of coherence in terms of meaning and vocabulary. This points to the challenge of specifying the boundary object sufficiently for problem-solving to occur while at the same time keeping the problem-framing sufficiently open to allow for sufficient fluidity for inscription and contestation by different stakeholders.

\section{Learning from failure}

In order to learn from experimentation, it is important to allow for risk-taking and, consequently, not to dismiss failure as necessarily a bad thing. While readily recognized as inevitable in the private sector, this is particularly challenging for local governments when public expenditure of tax payers' money is at stake. Rather than seeking to outlaw mistakes, local governments involved in experimentation should seek to reduce the costs of mistakes by learning from them and by learning to 'fail faster'. Therefore, transparency is crucial to allow for monitoring and evaluation of experiments to happen. Still, this is often seen as low status activities which, in the case of the Resilient Melbourne Strategy, were not set up as an integral part of the strategy. At best, monitoring and evaluation happens for the purpose of accountability not organizational learning. However, particularly actions with socio-cultural goals such as creating social cohesion are often long-term processes and difficult to assess in real- 
time. Moreover, barriers to organizational learning in local government are manifold - silo structures, staff turnover and the lack of time devoted to learning.

\section{Conclusions}

This paper has explored how governance experimentation has been deployed on urban resilience-building in the context of metropolitan Melbourne. It elucidates three organizational design principles that characterize the Resilient Melbourne strategy as governance experimentation: a participatory architecture based on cross-sectoral and institutionally diverse partnerships and networking, a thematic focus and platform based on multistakeholder engagement with boundary objects such as 'cycling network' or 'urban forest' and, finally, an emphasis on extensive deliberation in workshops and active feedback loops between strategy and actions, aimed at expedited collective learning.

The case studies in the context of Resilient Melbourne show that governance experimentation can be instrumental in breaking down institutional silos and relaxing the risk of institutional lock-in in the face of wicked urban problems by providing active learning platforms for multi-stakeholder cooperation and exchange. Particularly the case study 'metropolitan urban forest strategy' demonstrates how important openness for unconventional ways of thinking and practice is in contemporary urban planning. Ongoing exchange and engagement with a variety of stakeholders has proven to be crucial.

At the same time, the emphasis on tentative strategies, deliberation and social inquiry, exposes governance experimentation to significant vulnerability and risks for co-optation by vested interests and historically dominant institutional logics (especially in relation to urban planning and urban design as the case study 'metropolitan cycling network' has explored).

The paper sheds light on some of the critical challenges in implementing governance experimentation. Three important insights are:

1) Governance experimentation needs effective and active 'boundary management'. Novel organizational entities within local governments, such as the Resilient Melbourne Delivery Office, can fulfil this role, partly relying on the existing knowledge, capabilities and trust that local government holds with local stakeholders in the city. Organizational responsibility for boundary management in governance experimentation is however contingent on local institutional conditions and networks and could also evolve over time towards other stakeholders implied in the experimentation.

2) Governance experimentation needs flexible 'boundary objects' to transform understandings of urban systems. The resilience lens recasts and opens up for considerable interpretative flexibility around traditional urban systems - such as urban forest and cycling networks - across different stakeholder groups and the way these groups offer different inscriptions in terms of objectives, meanings and challenges. Implementation of strategy can thus be seen as an on-going negotiation and calibration of such boundary objects towards closure and a common understanding across multiple stakeholder groups.

3) 'Failure' is more often the rule rather than the exception in processes of experimentation and innovation. This is politically challenging especially in institutional contexts that are organized around short time horizons and principles of cost-efficiency. Monitoring and evaluation of actions should therefore be seen as an integral part of governance experimentation, not solely due to issues of accountability but primarily to allow for transparency, learning and reflexivity.

Reflecting on the two case studies unveils the importance of process analysis of single experimental actions, in addition to the traditional focus on outcomes and impact, in order to provide meaningful policy advise. The introduced framework is a helpful tool for planners, policy makers and researchers to analyze, monitor and adjust governance experimentations such as urban resilience actions, living labs, urban laboratories, or transition labs. Further research on the role of interactions between cities and regions or other spatial scales would further enrich the debate. 
Particularly, reflections on multi-level governance, 'scaling up' (Kythreotis 2018; Smeds \& Acuto 2018) and the role of global city networks such as 100 Resilient Cities, C40 or ICLEI (see Davidson et al. 2019) is needed.

Ultimately, driving urban transformations depends not only on the willingness by local governments to reflect on and innovate towards 'better' urban planning approaches, as SDG 11 has pointed out, but, perhaps more critically, on building capacity for innovation in local governments. Such structural capacity-building is urgently needed to move innovation in local government beyond the obvious rhetoric of innovative and experimental action. Apart from more inclusive, reflective and long-term oriented policy practices and repertoires, this requires also actual allocation of resources and budget. Without substantial, consistent and 'patient' investments in innovation capacity, governance experimentation will lack the longevity and scope for policy learning that supports the scaling and mainstreaming of experiments. This will, at the end of the day, determine whether governance experimentation amounts to transformative change or simply camouflages business-as-usual.

\section{Acknowledgements}

The authors thank all team members of the Resilient Melbourne Delivery Office (RMDO) for their openness and valuable insights and suggestions. Furthermore, they thank the guest editors of this special issue as well as the reviewers for helpful and constructive comments. Earlier versions of this paper were presented at the RSA Winter Conference and the Global Conference on Economic Geography, Cologne, in a session organized by Gernot Grabher and Oliver Ibert.

\section{References}

100RC (2019). 100 Resilient Cities. http://100resilientcities.org/buildingresilience-nature-practitioners-guide-action/ (accessed 20 February 2019).

Acuto, M. (2018). Why Cities Need Chief Exploration Officers. Scientific American. https://blogs. scientificamerican.com/observations/why-cities-need-chiefexploration-officers/. (accessed 20 February 2019).

Albrechts, L. (2004). Strategic (Spatial) Planning Reexamined. Environment and Planning B: Planning and Design, 31, 743-758. https://doi.org/10.1068/b3065
Arup (2019). Arup's City Resilience Index. Available online: https://www.arup.com/perspectives/city-resilience-index (accessed 20 February 2019).

Beilin, R., \& Wilkinson, C. (2015). Introduction: Governing for urban resilience. Urban Studies, 52, 12051217. doi:10.1177/0042098015574955

Berkes, F., \& Folke, C. (1998). Linking social and ecological systems for resilience and sustainability. In F. Berkes \& C. Folke (Eds.), Linking Social and Ecological Systems: Management Practices and Social Mechanisms for Building Resilience (pp. 1-25). Cambridge: Cambridge University Press.

Berkes, F. (2007). Understanding uncertainty and reducing vulnerability: lessons from resilience thinking. Natural Hazards, 41, 283-295. doi:10.1007/s11069-006-9036-7

Bos, A. J. J., \& Brown, R. R. (2012). Governance experimentation and factors of success in socio-technical transitions in the urban water sector. Technological Forecasting and Social Change, 79, 1340-1353.

Boschma, R. (2015). Towards an Evolutionary Perspective on Regional Resilience. Regional Studies, 49, 733751, doi:10.1080/00343404.2014.959481

Brand, F. S. \& Jax, K. (2007). Focusing the meaning(s) of resilience: resilience as a descriptive concept and a boundary object. Ecology and Society, 12.

Bulkeley, H., Castán Broto, V., \& Maassen, A. (2011). Governing urban low carbon transition. In H. Bulkeley, V. Castán Broto, M. Hodson, \& S. Marvin (Eds.), Cities and Low Carbon Transition (pp. 29-41). London: Routledge.

Bulkeley, H. \& Castán Broto, V. (2013). Government by experiment? Global cities and the governing of climate change. Transactions of the Institute of British Geographers, 38, 361-375. doi:10.1111/j.14755661.2012.00535.x

Bulkeley, H., Castan Broto, V., \& Maassen, A. (2014). Low-carbon transitions and the reconfiguration of urban infrastructure. Urban Studies, 51, 1471-1486.

Bulkeley, H., Marvin, S., Palgan, Y. V., McCormick, K., BreitfussLoidl, M., Mai, L., von Wirth, T., \& Frantzeskaki, N. (2018). Urban living laboratories: Conducting the experimental city? European Urban and Regional Studies. doi:10.1177/0969776418787222

Burch, S., Shaw, A., Dale, A. \& Robinson, J. (2014). Triggering transformative change: a development path approach to climate change response in communities. Climate Policy, 14, 467-487, doi:10.1080/14693062.2014.876342

Caprotti, F., \& Cowley, R. (2017). Interrogating urban experiments. Urban Geography, 38, 14411450, doi:10.1080/02723638.2016.1265870

Cash, D. W., Adger, W., Berkes, F., Garden, P., Lebel, L., Olsson, P., Pritchard, L. \& Young. O. (2006). Scale and cross-scale dynamics: governance and information in a multilevel world. Ecology and Society, 11.

Chelleri, L., Waters, J. J., Olazabal, M., \& Minucci, G. (2015). Resilience trade-offs: addressing multiple scales and temporal aspects of urban resilience. Environment and Urbanization, 27, 181198. https://doi.org/10.1177/0956247814550780

Coaffee, J. (2013). Towards Next-Generation Urban Resilience in Planning Practice: From Securitization to Integrated Place Making. Planning Practice \& Research, 28, 323339. doi:10.1080/02697459.2013.787693

Coaffee, J., Therrien, M., Chelleri, L., Henstra, D., Aldrich, D. P., Mitchell, C. L., Tsenkova, S. \& Rigaud, É. (2018). Urban resilience implementation: A policy challenge and research agenda for the 
21st century. Journal of Contingencies and Crisis Management, 26, 403-410. doi:10.1111/1468-5973.12233

Coenen, L., Raven, R., \& Verbong, G. (2010). Local niche experimentation in energy transitions: A theoretical and empirical exploration of proximity advantages and disadvantages, Technology in Society, 32, 295-302. doi:10.1016/j.techsoc.2010.10.006

Cote, M., \& Nightingale, A. J. (2012). Resilience thinking meets social theory: Situating social change in socio-ecological systems (SES) research. Progress in Human Geography, 36, 475489. doi:10.1177/0309132511425708

Cretney, R. (2014). Resilience for Whom? Emerging Critical Geographies of Socio-ecological Resilience. Geography Compass, 8, 627-640. doi:10.1111/gec3.12154

Davidson, K., \& Gleeson, B. (2018). New Socio-ecological Imperatives for Cities: Possibilities and Dilemmas for Australian Metropolitan Governance. Urban Policy and Research, 36, 230241. doi:10.1080/08111146.2017.1354848

Davidson, K., Coenen, L., Acuto, M., \& Gleeson, B. (2019). Reconfiguring urban governance in an age of rising city networks: A research agenda. Urban Studies. 56, 3540-3555. doi: 10.1177/ 0042098018816010

Davoudi, S. (2012). Resilience, a bridging concept or a dead end? Planning Theory and Practice, 13, 299-307.

Davoudi, S., Brooks, E., \& Mehmood, A. (2013). Evolutionary Resilience and Strategies for Climate Adaptation, Planning Practice $\mathcal{E}$ Research, 28, 307-322, doi: 10.1080/02697459.2013.787695

Duit, A., Galaz, V., Eckerberg, K., \& Ebbesson, J. (2010). Governance, complexity, and resilience, Global Environmental Change, 20, 363368. doi:10.1016/j.gloenvcha.2010.04.006

Duit A. (2016). Resilience Thinking: Lessons for public adminstration. Public Administration, 94: 364-380. doi:10.1111/padm.12182

Elmqvist, T., Andersson, E. Frantzeskaki, N., McPhearson, T., Olsen, P., Gaffney, O., Takeuchi, K. \& Folke, C. (2019). Sustainability and resilience for transformation in the urban century. Nature Sustainability, 2, 267-273.

Evans, J., Karvonen, A., \& Raven, R., (Eds.) (2016). The Experimental City. London: Routledge.

Fainstein, S. (2018). Resilience and justice: planning for New York City. Urban Geography, 39, 12681275, doi:10.1080/02723638.2018.1448571

Fastenrath, S., Coenen, L., \& Davidson, K. (2019). Urban Resilience in Action: the Resilient Melbourne Strategy as Transformative Urban Innovation Policy? Sustainability, 11, 693.

Ferraro, F., Etzion, D., \& Gehman, J. (2015). Tackling Grand Challenges Pragmatically: Robust Action Revisited. Organization Studies, 36, 363-390. doi:10.1177/0170840614563742

Flick, U., (2004). Triangulation in qualitative research. In U. Flick, E. von Kardorff, \& I. Steinke (Eds.), A Companion to Qualitative Research (pp. 178-183). London: Sage.

Folke, C. (2006). Resilience: The emergence of a perspective for socialecological systems analyses, Global Environmental Change, 16, 253267. doi.org/10.1016/j.gloenvcha.2006.04.002.

Frantzeskaki, N., Castán Broto, V., Loorbach, D., \& Coenen, L. (2017). Urban Sustainability Transitions. New York: Routledge.

Fuenfschilling, L., Frantzeskaki, N., \& Coenen, L. (2019). Urban experimentation \& sustainability transitions. European Planning Studies, 27, 219-228.

Garud, R. \& Karnøe, P. (2001). 'Path creation as a process of mindful deviation'. In R. Garud, \& P. Karnøe (Eds.), Path Dependence and Path Creation (1-38). Mahwah, NJ: Lawrence Earlbaum.
Garud, R., Kumaraswamy, A. \& Karnøe, P. (2010). Path Dependence or Path Creation? Journal of Management Studies, 47, 760-774. doi:10.1111/j.1467-6486.2009.00914.x

Hay, I., \& Muller, S. (2014). Questioning generosity in the golden age of philanthropy: Towards critical geographies of superphilanthropy. Progress in Human Geography, 38, 635653. doi:10.1177/0309132513500893

Hodson, M., Geels, F.W. \& McMeekin, A. (2017). Reconfiguring Urban Sustainability Transitions, Analysing Multiplicity. Sustainability 2017, 9.

Holling, C.S. (1973). Resilience and Stability of Ecological Systems. Annual Review of Ecology and Systematics. 4, 1-23.

IPCC (2018). Summary for urban policy makers. What the IPCC special report on global warming of $1,5^{\circ} \mathrm{C}$ means for cities. Available online: https://www.ipcc.ch/site/assets/uploads/sites/2/2018/12/SPM-forcities.pdf (accessed 12 October 2019)

Kythreotis, A.P. \& Bristow, G.I. (2017). The 'resilience trap': exploring the practical utility of resilience for climate change adaptation in UK city-regions, Regional Studies, 51, 15301541, doi:10.1080/00343404.2016.1200719

Kythreotis, A.P. (2018). Reimagining the urban as a dystopic resilient space: scalar materialities in climate knowledge, planning and politics. In Jonas, K., Ward, B. Miller, D. Wilson (Eds.) The Routledge Handbook on Spaces of Urban Politics (pp. 589-600). Oxon and New York: Routledge.

Leitner, H., Sheppard, E., Webber, S. \& Colven, E. (2018). Globalizing urban resilience, Urban Geography, 39, 1276-1284.

MacKinnon, D., \& Derickson, K. D. (2013). From resilience to resourcefulness: A critique of resilience policy and activism. Progress in Human Geography, 37, 253-270. doi:10.1177/0309132512454775

Martin, R., \& Sunley, P. (2015). On the notion of regional economic resilience: conceptualization and explanation, Journal of Economic Geography, 15, 1-42, doi:10.1093/jeg/lbu015

Matyas, D. \& Pelling, M. (2015). Positioning resilience for 2015: the role of resistance, incremental adjustment and transformation in disaster risk management policy. Disasters, 39, 1-18. doi:10.1111/disa.12107

McGuirk, P., Dowling, R., Brennan, C. \& Bulkeley, H. (2015). Urban Carbon Governance Experiments. Geographical Research, 53, 39-52. doi:10.1111/1745-5871.12098

Meerow, S. \& Newell, J. P. (2016). Urban resilience for whom, what, when, where, and why? Urban Geography, doi:10.1080/02723638.2016.1206395

Meerow, S., Newell, J.P., \& Stults, M. (2016). Defining urban resilience: A review. Landscape and Urban Planning, 147, 38-49. https://doi.org/10.1016/j.landurbplan.2015.11.011

Moore, T., de Haan, F., Horne, R., \& Gleeson, B. (2018). Urban Sustainability Transitions: Australian Cases- International Perspectives. Singapore: Springer Singapore.

Nevens, F., Frantzeskaki, N., Gorissen, L. \& Loorbach, D. (2013). Urban Transition Labs: co-creating transformative action for sustainable cities, Journal of Cleaner Production, 50, 111-122.

OECD (2019). Enhancing Innovation Capacity in City Government, OECD Publishing, Paris, https://doi.org/10.1787/f10c96e5-en.

Padgett, J., \& Ansell, C. (1993). Robust Action and the Rise of the Medici, 1400-1434. American Journal of Sociology, 98, 1259-1319.

Padgett, J. F., \& Powell, W. W. (2012). The problem of emergence. In J. F. Padgett \& W. W. Powell (Eds.), The Emergence of 
Organizations and Markets (pp. 1-29). Princeton, NJ: Princeton

University Press.

Pelling, M. \& Manuel-Navarrete, D. (2011). From resilience to transformation: the adaptive cycle in two Mexican urban centers. Ecology and Society, 16, 1-11.

Porter, L. \& Davoudi, S. (2012). The Politics of Resilience for Planning: A Cautionary Note. Planning Theory and Practice, 13, 329-333.

Raven, R., Sengers, F., Spaeth, P., Xie, L., Cheshmehzangi, A. \& de Jong, M. (2019). Urban experimentation and institutional arrangements, European Planning Studies, 27, 258281. DOI: $10.1080 / 09654313.2017 .1393047$

Resilient Melbourne (2019). Living Melbourne. Available online: https://resilientmelbourne.com.au/living-melbourne/ (accessed on 17 February 2019)

Resilient Melbourne (2019²). Resilient Melbourne Delivery Office. Annual Report 2018-19. Available online: https://resilientmelbourne.com.au/wpcontent/uploads/2019/10/Resilient-Melbourne-Annual-Report-201819-Full-Double-Spread-Version-Web.pdf

Resilient Melbourne (2016). Resilient Melbourne Strategy. Available online: https://resilientmelbourne.com.au/strategy/ (accessed 11 February 2019).

Rogers, P. (2015). Researching resilience: An agenda for change, Resilience, 3, 55-71. doi:10.1080/21693293.2014.988914

Schwanen, T. (2016). Rethinking resilience as capacity to endure, City, 20, 152-160, doi:10.1080/13604813.2015.1125718

Sengers, F., Berkhout, F, Wieczorek, A.J. \& Raven, R. (2016). Experimenting in the city. Unpacking notions of experimentation for sustainability. In: J. Evans, A. Karvonen \& R. Raven, (Eds.). The Experimental City ( $p p$. 15-31). London: Routledge.

Shaw, K. (2012). “Reframing” Resilience: Challenges for Planning Theory and Practice. Planning Theory \& Practice, 13, 308312. doi:10.1080/14649357.2012.677124

Shaw, K., \& Maythorne, L. (2013). Managing for local resilience: towards a strategic approach. Public Policy and Administration, 28, $43-65$.

Simmie, J. \& Martin, R. (2010). The economic resilience of regions: towards an evolutionary approach, Cambridge Journal of Regions, Economy and Society, 3, 27-43, doi:10.1093/cjres/rsp029

Smeds, E., \& Acuto, M. (2018). Networking Cities after Paris: Weighing the Ambition Urban Climate Change Experimentation. Global Policy, 4, 549-559.

Turnheim, B., Kivimaa, P., \& Berkhout, F. (2018). Beyond Experiments. In B. Turnheim, P. Kivimaa, \& F. Berkhout (Eds.), Innovating Climate Governance: Moving Beyond Experiments (pp. 1-26). Cambridge: Cambridge University Press.

UN (2015). United Nations. Transforming our world: the 2030 Agenda for Sustainable Development. Available online: http://www.un.org/ga/search/view_doc.asp?symbol=A/RES/70/1\&L ang $=\mathrm{E}$ (accessed 20 February 2019)

VIC Gov (2016). State Government of Victoria. Plan Melbourne. https://www.planmelbourne.vic.gov.au/the-plan (accessed on 20 February 2019)

Webb, R., Bai, X., Smith, M.S. et al. (2018). Sustainable urban systems: Co-design and framing for transformation. Ambio, 47, 57-77. doi:10.1007/s13280-017-0934-6

Welsh, M. (2014). Resilience and responsibility. The Geographical Journal, 180: 15-26. doi:10.1111/geoj.12012

Yin, R.K. (2014). Case Study Research Design and Methods, fifth ed. Thousand Oaks: Sage. 